\title{
The Effect of Probiotic Yoghurt on the Frequency of Salivary Candida
}

Lesan $\mathbf{S}^{1}$, Haji Fattahi $\mathbf{F}^{1^{*}}$, Rahbar $\mathbf{M}^{2}$, Mohammadi $\mathbf{S}^{3}$

1.Assistant Professor, Oral medicine Dept, Dental Branch of Tehran Islamic Azad University, Tehran, Iran

2. Professor, microbiologist, Tehran,Iran

3.Dentist

\section{ARTICLE INFO}

Article Type

Original Article

Article History

Received: Jan 2017

Accepted: Feb 2017

ePublished: Apr 2017

\section{Keywords:}

Oral candidiasis,

Probiotic,

Probiotic yoghurt

\section{ABSTRACT}

Background and aim: Oral candidiasis is the most common fungal disease, and it is often considered as a local opportunistic infection. Oral candidiasis is usually treated with local use of antifungal medications. Since probiotic bacteria have the ability to inhibit the growth of pathogens and modulate human immune responses, they could provide new possibilities in antifungal therapy. The aim of the present study was to examine the effect of probiotic yoghurt on the frequency of salivary candida.

Materials and methods: This randomized double-blind crossover clinical trial involved 34 healthy adults divided to two groups: 17 subjects in case group (probiotic yoghurt) and 17 subjects in control group (regular yoghurt). At the beginning of the experiment and after 3 weeks of intervention (consumption of regular or probiotic yoghurt), saliva samples were collected from both groups and candida colonies were counted. After a two-week wash out period, the groups were interchanged (crossover study design), and the sampling process was repeated. The data were analyzed using Mann-U-Whitney and Chi-square tests. The level of significance was set at $p<0 / 05$. Results: Variations of salivary candida equaled $1.8 \pm 9.3 \mathrm{cfu} / \mathrm{ml}$ in regular yoghurt group and $-3.8 \pm 7.9 \mathrm{cfu} / \mathrm{ml}$ in probiotic yoghurt group $(\mathrm{p}=0.01)$. The amount of salivary candida decreased in $47 \%$ of the cases in probiotic yoghurt group and in $29.4 \%$ of the cases in regular yoghurt group $(p=0.07)$.

Conclusion: The results of the present study showed that short-term consumption of probiotic yoghurt decreases the frequency of salivary candida colonies after 3 weeks. 


\section{Introduction:}

Oral candidiasis is the most common fungal disease, and it is often considered as a local opportunistic infection. ${ }^{(1,2)}$ The most common cause of oral candidiasis is Candida albicans, which is usually present in the oral cavity of half of healthy individuals in a non-pathologic status. Adherence and proliferation of candida are influenced by host's local and systemic factors. ${ }^{(1,3)}$

Individuals with a weak immune system, cancer patients, diabetics and patients with a history of long-term use of antibiotics are extremely susceptible to candidiasis, which can cause high incidence of morbidity and mortality. ${ }^{(4,5)}$

Overgrowth of candida in the oral cavity may transfer to distant organs. Oral candidiasis is usually treated with local use of antifungal medications. ${ }^{(1)}$

Nowadays, alternate methods such as bacteriotherapy and use of probiotic bacteria which are effective on oral ecology are being used clinically. According to the definition by WHO and FAO, the word "probiotic" describes microorganisms that if used in adequate quantity, they can have beneficial impacts on host health. ${ }^{(3,6-9)}$ Some lactobacillus species can adhere to mucosal epithelium and compete with candida at the adhesion area. Moreover, some types of lactobacilli produce different metabolites such as hydrogen peroxide (H2O2) and antifungal cyclic peptides, which inhibit the growth of fungi in vitro. ${ }^{(10)}$

Evaluations by Hatakka et al in Finland showed that short-term use of probiotic cheese in the elderly decreased the incidence of oral candida from $30 \%$ to $21 \%$ in case group while in control group, the number of candida increased from $28 \%$ to $34 \%$. $^{(11)}$ In a study by Dos Santos et al, the incidence of candida decreased by $46 \%$ in the oral cavity after the use of probiotics. ${ }^{(12)}$ Tang et al evaluated the inhibitory effect of 16 probiotic strains on proliferation of Candida albicans in vitro, and observed a significant decrease in the proliferation of Candida albicans by all the probiotic strains. ${ }^{(5)}$ Gil et al assessed the effect of vaginal lactobacilli, as potential probiotics against candida species, and showed that these probiotics have the ability to inhibit the growth and proliferation of pathogenic microorganisms. ${ }^{(13)}$ Hasslof et al assessed the inhibition of candida growth by commercial probiotic lactobacilli in vitro, and concluded that all the assessed lactobacilli strains reduced candida growth. The growth inhibition pattern was similar for all candida strains. ${ }^{(14)}$ However, in a study by Koll et al on the effect of different strains of lactobacilli in the oral cavity, different results were achieved and no inhibitory effect against candida growth was observed. ${ }^{(15)}$ To date, limited in- vivo evaluations have been performed on the effect of probiotics on candida in the oral cavity. ${ }^{(16)}$ Due to controversial results and limitations of previous studies, the present research aimed to evaluate the effect of short-term consumption of probiotic yoghurt on the number of salivary candida in adults, in comparison with the control group.

\section{Materials and methods:}

This experimental randomized double-blind crossover clinical trial involved 34 volunteers, considering the study design and determined after performing a pilot study. The aim and stages of the study were explained to all the participants, and written consent forms were received. This study has been approved by the ethics committee. The participants were healthy nonsmoker adults who had not consumed any systemic antibiotics or mouthwashes since 4 weeks before the intervention, and did not have any orthodontic appliances or removable prostheses in the oral cavity. Saliva sampling was performed in all the subjects before breakfast and while they were fasting, and the subjects were asked to brush their teeth without using toothpaste and to drink a glass of water. After one hour, non-stimulated whole saliva sampling was performed through spitting. ${ }^{(11)}$

The minimum amount of collected saliva was $0.7 \mathrm{ml}$. Afterwards, the saliva samples were immediately transferred to the microbiology laboratory within 2 hours.

Sabouraud Dextrose Agar culture medium (with chloramphenicol) was used for candida assessment. The saliva micropipettes and culture medium plates were labelled, and the saliva sam- 
ples were placed in the above-mentioned medium. The plates were incubated for 48 hours at 37 ${ }^{\circ} \mathrm{C}$, and then they were kept at room temperature for 5 days. After staining the colonies, colony counting was performed by microbiology specialists according to the number of colony-forming units in each milliliter (cfu/ml). Afterwards, the participants were divided to case and control groups according to random number table.

\begin{tabular}{llll}
\hline Group 1 & A & B & Code A: regular yoghurt \\
\hline Group 2 & B & A & Code B: probiotic yoghurt \\
\hline
\end{tabular}

The assessed yoghurts were regular low fat yoghurt and probiotic yoghurt (Damdaran Co.). Both yoghurts contained the same fat percentage equal to $1.4 \mathrm{~g} \%$. The probiotics in the yoghurt were lactobacillus acidophilus and bifidobacterium lactis with the concentration of $106 \mathrm{cfu} / \mathrm{ml}$ per gram, according to the technical report of the manufacturer. Group A were given regular low fat yoghurt (Damdaran Co.), and group B were given probiotic yoghurt (Damdaran Co.). Probiotic products had been omitted from the participants' diet since 2 weeks before the sampling. In addition, the participants were asked to maintain their normal diet, brush their teeth twice daily and not to use probiotic products.

The subjects consumed the assigned yoghurt for 3 weeks, $200 \mathrm{~g}$ a day, at dinner time. They were asked not to brush their teeth for at least one hour after yoghurt consumption and not to eat during this one hour. ${ }^{(17)}$ At the end of the third week, saliva samples were collected according to the previously explained sampling principles to evaluate the variables, and then microbiology assessment was performed. After a two-week wash out period, saliva sampling was performed again and the case and control groups were interchanged. According to previous instructions, the designated yoghurt was consumed for 3 weeks, $200 \mathrm{~g}$ daily, at dinner time. After three weeks, saliva sampling was performed again according to the previously explained sampling principles. The variations of candida numbers in the two groups were analyzed by Mann-U-Whitney test, and the decrease of candida amount was analyzed by Chi-square test.

The significance level was set at $\mathrm{P}<0.05$.

\section{Results}

This study was performed on 34 adults or 68 samples (considering the study design). 20\% of the participants were males and $80 \%$ were females, in the age range of $29.8 \pm 10.2$ years, with the minimum age of 23 years and maximum age of 55 years. 34 subjects had candida in the oral cavity.

The variations of salivary candida in the assessed groups are presented in Table 1, which shows that the number of salivary candida was equal in the two groups at the beginning of the experiment, while after intervention, in regular yoghurt group this amount was increased by $1.8 \mathrm{cfu} / \mathrm{ml}$, while in probiotic yoghurt group it decreased by $3.8 \mathrm{cfu} / \mathrm{ml}$. Mann-U-Whitney test proved that this difference is statistically significant $(\mathrm{p}=0.01)$.

Table 1- Amount of salivary candida ( $\mathrm{cfu} / \mathrm{ml})$ in the assessed groups

\begin{tabular}{cccc}
$\begin{array}{c}\text { Candida } \\
\text { Regular }\end{array}$ & $\begin{array}{c}\text { Before } \\
\dot{\mathrm{X}} \pm \mathrm{SD}\end{array}$ & $\begin{array}{c}\text { After } \\
\mathrm{X}=34\end{array}$ & $\begin{array}{l}\text { Variations } \\
\dot{\mathrm{X}} \pm \mathrm{SD}\end{array}$ \\
\hline $\begin{array}{c}\text { Probiotic } \\
\mathrm{N}=34\end{array}$ & $11 \pm 14.4 \pm 18.7$ & $12 \pm 19.1$ & $1.8 \pm 9.3$ \\
\hline $\mathrm{P}$-value & & $6.4 \pm 10.5$ & $-3.8 \pm 7.9$ \\
\hline
\end{tabular}

The numbers have been converted to $0.01 \mathrm{cfu} / \mathrm{ml}$

Candida variations (decreased- unaltered- increased) according to candida colony number in each sample after intervention in comparison with the initial colony number in each subject in the assessed groups are presented in Table 2, which shows that candida amount in regular yoghurt group was decreased in $29.4 \%$ of the subjects, and in probiotic yoghurt group in $47 \%$ of the subjects. Chi-square test showed that this difference is not statistically significant $(\mathrm{p}=0.07)$. 
Table 2- Frequency of the assessed individuals ac cording to candida variations by the type of yoghurt

\begin{tabular}{ccccc}
\hline $\begin{array}{c}\text { Candida } \\
\text { Yoghurt }\end{array}$ & $\begin{array}{c}\text { Decreased } \\
\text { Number (\%) }\end{array}$ & $\begin{array}{c}\text { Unaltered } \\
\text { Number (\%) }\end{array}$ & $\begin{array}{c}\text { Increased } \\
\text { Number (\%) }\end{array}$ & $\begin{array}{c}\text { Total } \\
\text { Number (\%) }\end{array}$ \\
\hline Regular & $10(29.4)$ & $11(32.4)$ & $13(38.2)$ & $34(100)$ \\
\hline Probiotic & $16(47)$ & $11(32.4)$ & $7(20.6)$ & $34(100)$ \\
\hline P-value & $\mathrm{P}=0.07$ & & & \\
\hline
\end{tabular}

\section{Discussion:}

This randomized double-blind crossover clinical trial assessed the effect of probiotic yoghurt on the frequency of salivary candida in healthy adults. This research showed that short-term use of probiotic yoghurt decreases the number of salivary candida in comparison with regular yoghurt consumption.

This result is in line with the findings of studies by Hatakka et al, ${ }^{(11)}$ Hasslof et al, ${ }^{(14)}$ Elahi et al, ${ }^{(18)}$ Dos Santos et al, ${ }^{(12)}$ Tang et al, ${ }^{(5)}$ and Kraft-Bodi et al ${ }^{(19)}$. Moreover, in studies by Mendoca et $\mathrm{al}^{(20)}$ and Ishikawa et al ${ }^{(21)}$, slight or moderate improvement of oral candidiasis was observed in patients treated with probiotics. In a research by Li et al, simultaneous use of antifungal medication and probiotics significantly reduced the amount of candida compared with the use of antifungal medication alone. ${ }^{(22)}$ In a study by Kumar et al, the use of probiotic supplements in children consuming broad-spectrum antibiotics significantly reduced candida colonization in rectal area and also reduced candiduria in comparison with placebo. ${ }^{(23)}$

Studies by Hatakka et al, ${ }^{(11)}$ Dos Santos et $\mathrm{al},{ }^{(12)}$ and Elahi et al ${ }^{(18)}$ were performed in vivo, while the other mentioned studies assessed the effect of different probiotic species on candida in vitro.

In a research by Ahola et al on the assessment of the effect of probiotic cheese on salivary candida in the elderly, no significant differences were observed in counting the number of salivary candida colonies in probiotic and control groups, and candida amount was decreased by $27 \%$ in all the cases irrespective of the intervention. Albeit, the mentioned study was a placebo-controlled research and many confounding factors had influenced its results. (24)

In the study by Dos Santos et al, $46 \%$ reduction in candida frequency in the oral cavity was observed after consuming probiotic products. ${ }^{(12)}$ In the mentioned assessment, the subjects consumed a prebiotic product for 20 days with the concentration of $2 \times 10^{7}$ to $2 \times 10^{9}$ $\mathrm{cfu} / \mathrm{ml}$. But the concentration of the probiotics used in the current study equaled $10^{6} \mathrm{cfu} / \mathrm{ml}$, while bifidobacterium probiotic strain was present in both probiotic products. ${ }^{(12)}$

Elahi et al assessed the mice affected with oral candidiasis, and found that candida amount decreased after the use of probiotic products which contained lactobacillus acidophilus. As mentioned earlier, this probiotic strain has also been assessed in the present research. ${ }^{(18)}$

Tang et al showed that in $10^{7}$ and $10^{9} \mathrm{cfu} / \mathrm{ml}$ concentrations, all lactobacilli, except lactobacillus acidophilus La-5 and lactobacillus reuteri, inhibited the growth of all the 5 strains of candida. Lactobacillus acidophilus is among the probiotics used in Damdaran yoghurt and it is recommended to separately assess the effect of this strain on candida in future investigations. ${ }^{(5)}$

In studies by Gil et al ${ }^{(13)}$ and Osset et al, ${ }^{(25)}$ no inhibitory effect by lactobacilli was observed against candida in agar plate method. However, in both studies the inhibitory effect of some types of lactobacillus on Candida albicans was determined.

The results of the studies by Strahinic et al, ${ }^{(26)}$ Koll et al, ${ }^{(15)}$ and Ahola et $\mathrm{al}^{(24)}$ contradicted our results. In the study by Koll et al, none of lactobacillus species inhibited Candida albicans growth. Albeit, dairy probiotic products were not used in the above study and other compounds were evaluated. ${ }^{(15)}$ The reason for differences between the results of the mentioned studies and the current research is the in-vitro nature of the mentioned studies and as stated earlier, the difference in culture technique has been effective in the inhibition of candida. Moreover, probiotic effect is strain-specific and accurate determination of probiotic sample is important from this perspective.

In the present study, candida frequency increased in $38 \%$ of the samples of control group, which is similar with the results of the study by Hatakka et al. ${ }^{(11)} \mathrm{How}-$ 
ever, this issue needs further assessment.

It is believed that part of the beneficial effects of probiotic bacteria is due to restoring the balance between microflora and immune system. Imbalance in normal microflora after antibiotic therapy is an important predisposing factor for spread of a localized candida infection, and treatment with probiotic microorganisms can have effective therapeutic impacts equal to preventive measures in such infections. ${ }^{(27)}$ There are different conclusions on how the probiotics inhibit candida growth. Candida albicans can produce organic acids such as pyruvate and acetate, and it is considered as an important collaborator for cariogenic pathogens. ${ }^{(14)}$ Lactic acid bacteria can produce various antimicrobial substances such as organic acids, $\mathrm{H} 2 \mathrm{O} 2$, carbon oxide, diacetyl, low molecular weight antibacterial substances, bacteriocin and adhesion inhibitors. ${ }^{(28,29)} \mathrm{H} 2 \mathrm{O} 2$ derived from lactobacillus can prevent candida albicans growth. ${ }^{(30)}$ Some studies have reported that $\mathrm{H} 2 \mathrm{O} 2$ alone cannot inhibit Candida albicans and that some lactobacillus species produce substances similar to bacteriocin which show high antimicrobial activity against Candida albicans. ${ }^{(31)}$

In addition, by producing lactic acid, lactobacillus inhibits candida's metabolic activity. ${ }^{(29)}$ Some studies have reported increased levels of $\operatorname{sgA}$ against candida with the help of probiotics, which inhibit candida growth in the oral cavity. ${ }^{(18,32)}$ Probiotics decrease candida biofilm formation through decreasing fungal hyphae formation. ${ }^{(33,34)}$ Probiotic bacteria modulate cell-mediated and humoral immune responses against Candida albicans. ${ }^{(35)}$

Other studies have shown that the ability of probiotics to prevent Candida albicans adhesion to host cells in most infections, is a primary step. Moreover, it has been shown that butyric acid produced by some probiotic species can inhibit germ tube formation by fungi. ${ }^{(5)}$

The antifungal activity of Nystatin is directly correlated with its duration of contact with tissue, and since patients tend to swallow this drug in suspension form, this duration is often minimized. Also, Nystatin products contain high amount of sugar and should be prescribed cautiously for dentulous individuals or patients pre- senting with xerostomia. Nystatin and Clotrimazole vaginal pills which lack sweeteners are hard to use because of the drug form and special taste. ${ }^{(36)}$ Extensive immunosuppressive treatments have increased the number of patients with localized candidiasis during the recent years. Since the number of various candida specifies which are resistant against antifungal drugs is increasing, we need new solutions to stop and treat the infections caused by these pathogens. Probiotic bacteria have not been considered much during the last two decades; however, dairy products that contain these microorganisms are increasing nowadays. Due to the ability of probiotic bacteria to inhibit pathogens growth and modulate human immune responses, these bacteria can provide new possibilities in antifungal treatments. ${ }^{(27)}$

Further assessment of probiotics effect on salivary candida is recommended. It is advised to evaluate the effect of various probiotic strains on different candida species one by one. Furthermore, considering that intervention in in-vivo studies as well as the current research lasted for 3 weeks, it is also recommended to perform sampling and colony counting during intervention, to determine the exact time of probiotics action. In addition, other dairy products such as probiotic cheese and diluted yoghurt should also be evaluated. Consumption of probiotic yoghurt should be included in routine diet, especially as a prophylactic agent in individuals with a weak immune system. In the present study similar to the research by Kraft-Bodi et al, ${ }^{(19)}$ the phenotypic characteristics of candida have not been evaluated because of the use of agar culture medium; however, this evaluation is recommended in future studies. Unlike vulvovaginal candidiasis, there are few studies available regarding the use of probiotic bacteria for prevention and treatment of oral candidiasis, and related in-vivo studies are even more limited in number, which emphasizes the importance of the present study.

\section{Conclusion:}

The results of the present study showed that short-term consumption of probiotic yoghurt decreases the number of salivary candida colonies 
after 3 weeks.

Acknowledgments:

Our appreciation is extended to all the participants of this study. The present research is derived from General Dentistry thesis no. 358-5; Dental branch of Tehran, Islamic Azad University

\section{Conflicts of Interest:}

the authors of this manuscript certify that they have no conflicts of interest regarding this research.

\section{References:}

1. Yamamoto T. Oral candidiasis: clinical features and control. Rinsho Byori 2010;58(10):1027-34.

2. Dangi YS, Soni ML, Namdeo KP. Oral Candidiasis: A Review. International Journal of Pharmacy and Pharmaceutical Sciences 2010; 2(4):36-41.

3. Twetman S, Stecksén-Blicks C. Probiotics and oral health effects in children. Int $\mathrm{J}$ Paediatr Dent 2008;18(1):3-10.

4. Calderone RA, Fonzi WA. Virulence factors of Candida albicans. Trends in microbiology 2001;9(7):32735 .

5. Tang H, Ren J, Yuan J, Zeng B, Wei H. An in vitro assessment of inhibitory effect of 16 strains of probiotics on the germination of Candida albicans. Afr J Microbiol Res 2010;4(12):1251-6.

6. Saraf K, Shashikanth MC, Priy T, Sultana N, Chaitanya NC. Probiotics- do they have a role in medicine and dentistry? J Assoc Physicians India 2010;58:488-90.

7. Brown AC, Valiere A. Probiotics and medical nutrition therapy. Nutrition in clinical care 2004;7(2):56-68. 8. Stamatova L, Meurman J.H. Probiotics: health benefits in the mouth. Amerikan journal of dentistry 2009;22(6):329-38.

9.Ohshima T, Kojima Y, Seneviratne CJ, Maeda N. Therapeutic application of symbiotics, a fusion of probiotics and prebiotics, and biogenics as a new concept for oral candida infections: A mini review. Frontiers Microbiology 2016;7:

10.Haukioja A. Probiotics and oral health. Eur J Dent 2010;4(3):348-55.

11. Hatakka K, Ahola AJ, Yli-Knuuttila H, Richardson M, Poussa T, Meurman JH, et al. Probiotics reduce the prevalence of oral candida in the elderly--a randomized controlled trial. J Dent Res 2007;86(2):125-30.

12. Dos Santos AL, Jorge AO, Dos Santos SS, Silva CR, Leão MV. Influence of probiotics on Candida presence and IgA anti-Candida in the oral cavity. Braz J Microbiol 2009;40(4):960-4.
13. Gil NF, Martinez RC, Gomes BC, Nomizo A, De Martinis EC. Vaginal lactobacilli as potential probiotics against Candida spp. Braz J Microbiol 2010;41(1):6-14.

14.Hasslöf P, Hedberg M, Twetman S, Stecksén-Blicks C. Growth inhibition of oral mutans streptococci and candida by commercial probiotic lactobacilli--an in vitro study. BMC oral health 2010;2(10):18.

15.Kõll P, Mändar R, Marcotte H, Leibur E, Mikelsaar M, Hammarström L. Characterization of oral lactobacilli as potential probiotics for oral health. Oral Microbiol Immunol 2008;23(2):139-47.

16. Flichy-Fernández AJ, Alegre-Domingo $T$, Peñarrocha-Oltra D, Peñarrocha-Diago M. Probiotic treatment in the oral cavity: an update. Med Oral Patol Oral Cir Bucal 2010 1;15(5):e677-80.

17. Montalto M, Vastola M, Marigo L, Covino $\mathrm{M}$, Graziosetto $\mathrm{R}$, Curigliano V, et al. Probiotic treatment increases salivary counts of lactobacilli: a double-blind, randomized, controlled study.Digestion 2004;69(1):53-6. 18. Elahi S, Pang G, Ashman R, Clancy R. Enhanced clearance of candida albicans from the oral cavities of mice following oral administration of lactobacillus acidophilus. Clin Exp Immunol 2005;141(1):29-36.

19. Kraft-Bodi E, Jørgensen MR, Keller MK, Kragelund C, Twetman S. Effect of probiotic bacteria on oral candida in Frail elderly. J Dent Res 2015;94(9 Suppl):1815-65

20- Mendoca FH, Santos SS, Faria Ida S, Gonçalves e Silva CR, Jorge AO, Leao MV. Effect of probiotic bacteria on candida presence and $\operatorname{IgA}$ anti-candida in the oral cavity of elderly. Braz Dent J 2012;23(5): 534-8.

21.Ishikawa KH, Mayer MP, Miyazima TY, Matsubara VH, Silva EG, Paula CR, et al . A multispecies probiotics reduces oral candida colonization in denture wearers . J Prosthodont 2015;24(3):194-9.

22. Li D, Li Q, Liu C, Lin M, Li X, Xiao X, et al. Efficacy and safety of probiotics in the treatment of candida-associated stomatitis. Mycoses 2014;57(3):141-6. 
23. Kumar S, Bansal A, Chakrabarti A, Singhi S. Evaluation of efficacy of probiotics in preventation of candida colonization in a PICU- A randomized controlled trial. Crit Care Med 2013;41(2):565-72.

24. Ahola A.J, Yli-Knuuttila H, Suomalainen T, Poussa T, Ahlström A, Meurman J.H, et al. Short-term consumption of probiotic-containing cheese and its effect on dental caries risk factors Arch Oral Biol 2002;47(11):799804.

25.Osset J, Gracia E, Bartolome RM, Andreu A. Role of Lactobacillus as protector against vaginal candidiasis. Med Clin 2001;117(8):285-8.

26. Strahinic L, Busarcevic M, Pavlica D, Milacin J, Golic N, Topisirovic L. Molecular and biochemical characterization of human oral lactobacilli as putative probiotic candidate. Oral Microbiol Imounol 2007;22(2):111-7.

27.Mailander-Sanches D, Wagener J, Schaller M. Potential role of probiotic bacteria in treatment and prevention of localized candidosis. Mycoses 2012;55(1):17-26.

28.Meurman JH, Stamatova L. Probiotics : Contributions to oral health. Oral Dis 2007;13(5):443-51.

29.Köhler GA, Assefa S, Reid G . Probiotic interference of lactobacillus rhamnosus GR-1 and lactobacillus reutreiRC-14 with the opportunistic fungal pathogen candida albicans. Infect Dis Obstet Gynecol 2012;2012:636474.

30.Strus M, Kucharska A, Kukla G, Brzychczy-Wolch M, Maresz K, Heszko pB. The inviro activity of vaginal Lactobacillus with probiotic properties against candida. Infect Dis Obset Gynecol 2005;13(2):69-75.

31.Kaewsrichan J, peeyaranjarassri K, Kongpraserkit J. Selection and identification of anaerobic Lactobacilli producing inhibitory compounds against vaginal pathogens. FEMS Immunol Med Microbiol 2006;48(1):75-83. 32.Ericson D, Hamberg K, Bratthall G, Sinkiewicz-Enggren G, Ljunggren L. Salivary IgA response to probiotic bacteria and mutans streptococci after the use of chewing gum containing lactobacillus reuteri. Pathog Dis 2013;68(3):82-7.

33.Matsubara VH, Bandara HM, Mayer MP, Samaranayake LP.Probiotics as antifungals in mucosal candidiasis. Clin Infect Dis 2016 1;62(9):1143-53.

34.Ujaoney S, Chandra J, Faddoul F, Chane M, Wang J, Taifour L, et al. In vitro effect of overthe-counter probioticson the ability of candida albicans to form biofilmon denture strips. J Dent Hyg 2014;88(3):183-9.

35.Wagner RD, Warner T, Pierson C, Roberts L, Farmer J, Dohnalek M, et al. Biotherapeutic effects of probiotic bacteria on candidiasis in immunodeficient mice. Rev Iberoam Micol 1998;15(4):265-70.

36.Wiseman M. The treatment of oral problems in the palliative patient. J Can Dent Assoc 2006;72(5):453-8. 